\title{
LETTERS
}

\section{Assessing the Accuracy of Three National Physician Sampling Frames}

\author{
Mary Henderson, PhD \\ American Medical Association Health Solutions, Chicago, IL, USA.
}

J Gen Intern Med 30(10):1402

DOI: $10.1007 / \mathrm{s} 11606-015-3483-3$

(c) Society of General Internal Medicine 2015

$\mathrm{T}_{\mathrm{w}}$ o the Editor:

We feel it is important to provide context and clarity on the use of the AMA Masterfile in the study by DesRoches et al. ${ }^{1}$ The study's methodology has a core weakness that inhibits a meaningful comparison of the disparate databases. We believe the author should have explicitly noted the key differences in the databases that we believe influenced the outcome of the study.

The authors selected the AMA's Physician Preferred Mailing Address (PPMA) to compare against practice addresses from National Plan and Provider Enumeration System and SK\&A despite the fact that the AMA PPMA is unique. Of the three databases examined, only the AMA Masterfile allows physicians the choice to include a preferred mailing address, which can, and often does, include a nonpractice address. The fact that the non-practice addresses in the AMA PPMA cannot be matched to NPPES or SK\&A or validated by calling the physician's office, does not make them inaccurate, as suggested by the study. The AMA utilizes its PPMA to successfully route over 25 million mail pieces to physicians annually. Additionally, the AMA processes over 65 million updates to the Masterfile annually, including approximately 31,000 address changes per month. This is the result of compiling data from over 2,000 public and syndicated data sources, including NPPES, and approximately 500,000 inbound and outbound phone interactions with physicians and their practices.

For purposes of this study, it would have been more appropriate to include the AMA's Primary Office Location (POLO), which is more in line with the type of address found in the NPPES and SK\&A datasets. It is also important to note that Medical Marketing Service (MMS), the AMA Database Licensee that provided data for the study, did not return information for physicians who were deceased or retired, or who indicated that they do not wish to receive mail, which is important to factor into the NPI match rate results.

There are numerous databases that contain information on physicians. It is important to understand the details of how each database is compiled and maintained, as well as the definitions of the various data elements included. Having this knowledge will allow researchers to make meaningful comparisons and intelligent decisions on what source best meets the needs of their project.

Corresponding Author: Mary Henderson, PhD; American Medical Association Health Solutions, $330 \mathrm{~N}$ Wabash Avenue, Suite 39300, Chicago, IL 60611-5885, USA (e-mail: mary.henderson@amaassn.org).

\section{REFERENCE}

1. DesRoches CM, Barrett K, Harvey B, et al. The Results Are Only As Good As The Sample. Journal of General Internal Medicine. 2015. doi:10.1007/ s11606-015-3380-9. 